\title{
Vulnerability to drought-induced cavitation in shoots of two typical shrubs in the southern Mu Us Sandy Land, China
}

\author{
LI Yangyang ${ }^{1,2^{*}}$, CHEN Weiyue $^{3}$, CHEN Jiacun $^{2}$, SHI Hui ${ }^{4}$ \\ ${ }^{1}$ State Key Laboratory of Soil Erosion and Dryland Farming on the Loess Plateau, Northwest A\&F University, Yangling \\ 712100, China; \\ ${ }^{2}$ Institute of Soil and Water Conservation, Chinese Academy of Sciences, Yangling 712100, China; \\ ${ }^{3}$ College of Forestry, Northwest A\&F University, Yangling 712100, China; \\ ${ }^{4}$ School of Environmental and Municipal Engineering, Xi'an University of Architecture and Technology, Xi'an 710055, China
}

Abstract: Salix psammophila and Caragana korshinskii are two typical shrubs in the southern $\mathrm{Mu}$ Us Sandy Land of China which are threatened by increasing water deficits related to climate change and large-scale human activities (e.g. coal mining and oil exploitation). In this study, we assessed their vulnerability to xylem embolism and the related anatomical traits in two-year-old regenerated shoots of these two shrubs to understand how they cope with drought environment. We also evaluated the in situ hydraulic safety margins to hydraulic failure from measurements of annual predawn and midday leaf water potentials. The results showed that $S$. psammophila stems had a higher water transport capacity than $C$. korshinskii stems. The stem xylem water potentials at $12 \%, 50 \%$ and $88 \%$ loss of conductivity were $-1.11,-1.63$ and $-2.15 \mathrm{MPa}$ in S. psammophila, respectively, and $-1.37,-2.64$ and $-3.91 \mathrm{MPa}$ in C. korshinskii, respectively. This suggested that C. korshinskii was more resistant to cavitation than S. psammophila. Compared with $S$. psammophila, C. korshinskii had shorter maximum vessel length, lower vessel density, smaller conductive area and higher wood density, which may contribute to its more resistant xylem. The in situ hydraulic safety margins indicated that even during the driest periods, both shrubs lived well above the most critical embolism thresholds, and the hydraulic safety margin was wider in $C$. korshinskii than in S. psammophila, suggesting that the regenerated shoots of both shrubs could function normally and $C$. korshinskii had greater hydraulic protection. These results provide the basis for an in-depth understanding of the survival, growth and functional behavior of these two shrubs under harsh and dry desert environments.

Keywords: Salix psammophila; Caragana korshinskii; hydraulic vulnerability; xylem anatomy; hydraulic safety margin

Citation: LI Yangyang, CHEN Weiyue, CHEN Jiacun, SHI Hui. 2016. Vulnerability to drought-induced cavitation in shoots of two typical shrubs in the southern Mu Us Sandy Land, China. Journal of Arid Land, 8(1): 125-137. doi: 10.1007/s40333-015-0056-6

The Mu Us Sandy Land of China lies in the central and southeastern portion of the Ordos Ecotone, a transitional zone connecting the Gobi desert in the northwest with the forest steppe in the southeast (Walter and Box, 1983). The annual precipitation in this area is generally less than $400 \mathrm{~mm}$. Water deficiency is thus the critical factor limiting the growth, reproduction and

\footnotetext{
*Corresponding author: LI Yangyang (E-mail: yyli@ms.iswc.ac.cn)

Received 2015-03-04; revised 2015-04-24; accepted 2015-07-23

(C) Xinjiang Institute of Ecology and Geography, Chinese Academy of Sciences, Science Press and Springer-Verlag Berlin Heidelberg 2016
} 
survival of plants in this area, and it exacerbates for the decrease of groundwater level caused by local energy development in recent years, such as coal mining and oil exploitation (Fan, 2007). Salix psammophila and Caragana korshinskii, two dominant deciduous shrubs in the Mu Us Sandy Land, belong to the Salicaceae and Fabaceae families, respectively. Both species play important roles in soil and water conservation, sand-fixing and wind-blocking, and also help to increase the incomes of local farmers (S. psammophila as an important bio-energy material and C. korshinskii as a good forage). Studies on the adaptations of these two shrubs to the dry sandy environment in the $\mathrm{Mu}$ Us Sandy Land would be especially useful for understanding the sand-water-shrub relationships and for contributing to the rational management of afforested shrub stands. Various studies have examined how these two species cope with drought based on their root distribution (Zhang et al., 2010), water uptake source (Wang et al., 2013), foliar anatomy, leaf water relationship, photosynthetic and transpirational traits (Dong and Zhang, 2001; Xu and Shan, 2004), leaf osmoregulation ability and cell membrane stability (Ma et al., 2008). The hydraulic traits of these two species, however, only have received little attention.

The capacity of system for transporting water between the soil and leaves sets a fundamental limitation to the ability of plants to survive and grow under water-limited conditions. As soil dries, the xylem vessels come under increasing physical tension, which, when great enough, causes the water column to be broken and become air-filled, resulting in cavitation and loss of hydraulic conductivity (Tyree and Sperry, 1989). The reduced hydraulic conductivity can reduce stomatal conductance and photosynthetic capacity of plants (Brodribb and Field, 2000; Pratt et al., 2005). Cavitation and embolism of the stem xylems thus have the potential to affect the growth, reproduction and survival of plants. The resistance to cavitation is closely associated with drought resistance and geographical distribution of plants (Pockman and Sperry, 2000; Cochard et al., 2007, 2008). Xylem hydraulic vulnerability has been well studied on trees than on shrubs. Although shrubs are more resistant to cavitation than trees (Maherali et al., 2004), cavitation resistance (usually estimated by water potential at $50 \%$ loss of conductivity, $\psi_{50}$ ) varies widely among the shrub species. For example, $\psi_{50}$ varied from -0.9 to $-11.0 \mathrm{MPa}$ in 26 chaparral species in southern California (Jacobsen et al., 2007), indicating that $\psi_{50}$ is a highly species-specific trait.

The air-seeding hypothesis states that when gas is pulled into a water-filled xylem conduit from an adjacent gas-filled cell or intercellular space, cavitation occurs if negative pressure within the water-filled conduit exceeds the cohesive bonds between water molecules at the gas-water interface of the largest pore in a xylem pit membrane (Zimmermann, 1983; Sperry and Tyree, 1988). The risk of cavitation may therefore be linked to the pitted area of xylem conduits. A larger and longer conduit may be more likely to contain a more vulnerable pit pore somewhere along its length (Hargrave et al., 1994; Tyree et al., 1994; Sperry et al., 2005). Hydraulically efficient xylems with longer and wider conduits may thus be more susceptible to cavitation. Cavitation may also occur when negative pressure overcomes the ability of xylem conduit walls to resist collapse (Hacke et al., 2001; Cochard et al., 2004; Brodribb and Holbrook, 2005). Wood density and conduit-wall reinforcement are thus closely associated with the resistance to drought-induced embolism. The macroscopic and microscopic traits that correlate with xylem vulnerability to cavitation may vary depending on the genus and species.

Plants mainly depend on two mechanisms to alleviate the threat of cavitation: (1) stomatal regulation, which constrains xylem tension to a range that prevents an excessive loss of stem conductivity from embolism; and (2) structural reinforcement of the xylem. Other mechanisms such as leaf shedding, water storage and refilling are also important for plants (Mayr et al., 2006; Meinzer et al., 2009). The hydraulic safety margin is usually defined as the difference between the typical minimum value of xylem water potential experienced by a species in the field $\left(\psi_{\min }\right)$ and the level of water stress leading to hydraulic failure (usually $\psi_{50}$ ). Using the $\psi_{\min }$ can make the estimation of the hydraulic safety margin robust across ecosystems and biomes, because $\psi_{\min }$ incorporates the variability of both soil types and vapor pressure deficit (Delzon and Cochard, 2014). This safety margin is typically positive and closely associated with drought adaptation and global drought-induced mortality (Choat et al., 2012; Nardini et al., 2013). Plants with narrow safety margins usually experience large amounts of embolism in their respective 
environments and therefore have a high risk of hydraulic failure. Therefore, an interspecific comparison of hydraulic safety margins is necessary to clarify the species-specific mechanism of drought resistance and their potential vulnerability to drought.

The limited reports on hydraulic vulnerability of S. psammophila and C. korshinskii indicated that $S$. psammophila is highly vulnerable to cavitation (Ogasa et al., 2013), and a progressive loss of stem hydraulic conductivity with age in C. korshinskii is associated with a decrease in the photosynthetic rate of resprouts, suggesting the importance of embolism in limiting the height growth of C. korshinskii resprouts (Fang et al., 2013). Resistance to cavitation is an important determinant of drought resistance for plant species, but it is not systematically compared in these two major shrubs in the field. Thus, we evaluated and compared the hydraulic transport efficiency and vulnerability in stems of $S$. psammophila and C. korshinskii to drought-induced cavitation. The specific objectives of this study were to: (1) compare the vulnerability to embolism and related xylem anatomy in two-year-old stems of mature S. psammophila and $C$. korshinskii shrubs; and (2) estimate the in situ minimum safety margin to evaluate if these two species are living close to their hydraulic limits.

\section{Materials and methods}

\subsection{Study area and plant materials}

The study was carried out in the Liudaogou watershed of Shenmu county $\left(38^{\circ} 46^{\prime}-38^{\circ} 51^{\prime} \mathrm{N}\right.$, $110^{\circ} 21^{\prime}-110^{\circ} 23^{\prime} \mathrm{E} ; 1,274 \mathrm{~m}$ asl), Shaanxi province, China. This area is situated in the transitional zone between the Loess Plateau and the Mu Us Sandy Land, and is a typical wind-water erosion crisscross region. It is characterized by a temperate semi-arid climate with an annual mean temperature of $8.4^{\circ} \mathrm{C}$. Mean annual precipitation in 1952-2013 was $437 \mathrm{~mm}$, with more than $70 \%$ of it occurring between July and September. The potential annual evapotranspiration is approximately $1,800 \mathrm{~mm}$.

Two adjacent stands of $S$. psammophila and C. korshinskii, planted in the watershed in the 1970s were selected for this study. The conservation density was 355 plants $/ \mathrm{hm}^{2}$ for $S$. psammophila stand and 3,240 plants $/ \mathrm{hm}^{2}$ for C. korshinskii stand. The understory plants were mainly grasses and forbs, such as Artemisia desertorum, Hedysarum scoparium, Setaria viridis, Oxytropis gracillima, Heteropappus hispidus, Astragalus melilotoides, Cynanchum auriculatum and Ixeris denticulate. Both stands are located on relatively flat sand dunes and the soil texture belongs to loamy sand. Soil moisture contents within 3-m depth on 20 June 2014 (dry season) were $7.59 \%$ and $9.68 \%$ for S. psammophila and C. korshinskii stands, respectively. Hydraulic and anatomical measurements were conducted from May to August 2014 on two-year-old shoots regenerated from the branching bases of ten randomly selected plants per species. Morphometric data for the sampled shrubs are presented in Table 1.

\subsection{Environmental variables}

Environmental data were collected from a nearby field microclimate station. Total solar radiation $\left(R_{\mathrm{S}}\right)$ was measured with an Apogee20 PRY-P pyranometer (CS300, Apogee Instruments Inc., Logan, Utah, USA); air temperature and relative humidity were measured with a temperature and humidity probe (HMP155A, Vaisala Com., Helsinki, Finland); and precipitation was monitored by a tipping-bucket rain gauge (TE525MM, Texas Electronics, Dallas, Texas, USA). Data were recorded every $10 \mathrm{~s}$ and stored as $10 \mathrm{~min}$ averages or totals by CR1000 data loggers (Campbell Scientific, Shepshed, UK).

\subsection{Physiological and anatomical measurements}

\subsubsection{Maximum vessel length and vessel length distribution}

The maximum vessel length was determined in six two-year-old regenerated branches from six shrubs per species by the air perfusion technique (Ewers and Fisher, 1989). Briefly, the basal end of each branch was infused with compressed air at $0.1 \mathrm{MPa}$, while the apical end was immersed in water. The branch was successively shortened by $10-\mathrm{mm}$ sections until air bubbles were seen. The remaining sample length was defined as the maximum vessel length of the sample. 
Table 1 Morphometric data of the sampled plants

\begin{tabular}{|c|c|c|c|c|}
\hline \multirow{2}{*}{ Species } & Basal branch diameter & Crown diameter & Height & \multirow{2}{*}{$\begin{array}{c}\text { Branching } \\
\text { (shoots/plant) }\end{array}$} \\
\hline & \multicolumn{3}{|c|}{$(\mathrm{m})$} & \\
\hline S. psammophila & $0.126 \pm 0.005$ & $3.86 \pm 0.29$ & $3.0 \pm 0.1$ & $37 \pm 5$ \\
\hline C. korshinskii & $0.102 \pm 0.007$ & $2.24 \pm 0.42$ & $1.8 \pm 0.1$ & $20 \pm 3$ \\
\hline
\end{tabular}

Note: Mean \pm SE for ten plants per species.

The distribution of vessel lengths was measured by the modified air method (Wang et al., 2014) on the samples for the above-mentioned measurements of maximum vessel length. The bubbles flowing out from the basal end were collected in a volumetric cylinder by the water displacement method, and the volume of air was determined when the water levels were the same inside and outside the cylinder. The air flow rate, $Q(\mathrm{~mL} / \mathrm{min})$ was measured at different stem lengths with constant air pressure at the inlet and outlet ends. Under such conditions of constant drops in air pressure, the hydraulic conductivity of the cut open vessels to the air, $C$, should be proportional to $Q_{\mathrm{x}}$, where $x$ is the stem length at which the air flow rate was measured. The values of $C$ and $Q_{x}$ can be calculated using the theory of Cohen et al. (2003):

$$
C=C_{0} \exp (-k x), \quad(1) ; \quad Q_{x}=Q_{0} x_{0} \exp (-k x) .
$$

Where, $x$ is the stem length; $C_{0}$ and $Q_{0}$ are the limiting conductivity and limiting air flow rate, respectively as $x$ approaches zero $\left(x_{0}\right)$; and $k$ is an extinction coefficient. The plot of the natural $\log$ of $C$ versus $x$ was linear, from which $k$ can be determined from the slope (Fig. 1). The mode of the vessel length, $L_{\text {mode }}$, was $-1 / k$. The mean vessel length can be calculated as $L_{\text {mean }}=2 L_{\text {mode }}$.

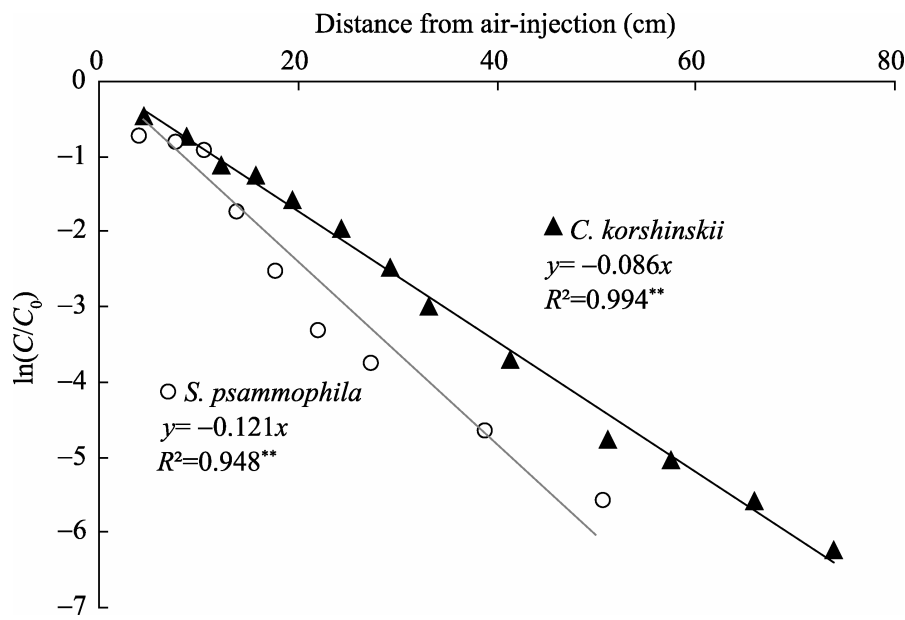

Fig. 1 Two examples of air-injection data for the determination of vessel length distribution. The $\mathrm{x}$-axis is the distance from air-injection $(x)$; and the $y$-axis is the natural $\log$ of $C$ (pneumatic conductivity) divided by $C_{0}$ (the limiting value of $C$ as $x$ approaches zero). $C_{0}$ was derived from the y-intercept of the regression of $\ln C$ versus $x$. The slopes of the regression lines are given in the figure, and the mean vessel length is $-2 / \mathrm{slope}(\mathrm{cm})$. $^{* *}$ means significance at $P<0.01$ level.

\subsubsection{Seasonal leaf water potential $\left(\psi_{1}\right)$}

Predawn and midday $\psi_{1}$ were measured at intervals of 15-20 days by a Scholander-type pressure chamber (PMS 1000, PMS Instruments, Corvalis, Oregon, USA) on four plants of each species. Predawn samples were collected on sunny days before sunrise between 05:00 and 05:30, and midday samples were collected between 13:00 and 14:00 on the same day. Three to four leaves per plant were collected at each sampling time from the south-facing side of the crowns, then bagged and immediately measured.

1.3.3 Predawn specific hydraulic conductivity $\left(K_{\mathrm{s}}\right)$ and native embolism

Samples for measuring predawn hydraulic conductivity and native embolism were collected at 
the same time as those for predawn $\psi_{1}$. Hydraulic conductivity was determined on six branches from six plants of each species from 15 June to 15 July 2014. Shoots longer than $1.4 \mathrm{~m}$ (the air-injection experiments indicated that the maximum vessel lengths for S. psammophila and $C$. korshinskii were 1.08 and $0.71 \mathrm{~m}$, respectively) were cut under water in the early morning, wrapped into plastic bags and then transported to the laboratory within $30 \mathrm{~min}$ after excision with the cut basal ends of the branches under water. Branch segments longer than $1.3 \mathrm{~m}$ for $S$. psammophila and $1.0 \mathrm{~m}$ for C. korshinskii were excised in the laboratory under water from the collected branches. The samples were debarked, and their ends were trimmed with a razor blade and then mounted on a XYL'EM apparatus (Bronkhorst, Montigny-les-Cormeilles, France) for measurement of hydraulic conductivity $\left(K_{\mathrm{h}}\right)$. $K_{\mathrm{h}}$ was determined at a hydrostatic pressure gradient of ca. $3 \mathrm{kPa}$ with a degassed and filtered $(0.22 \mu \mathrm{m})$ solution of $20 \mathrm{mmol} / \mathrm{L} \mathrm{KCl}$ and 1 $\mathrm{mmol} / \mathrm{L} \mathrm{CaCl}_{2}$. Then, $K_{\mathrm{h}}$ was converted to $K_{\mathrm{s}}(\mathrm{kg} /(\mathrm{s} \cdot \mathrm{MPa} \cdot \mathrm{m}))$ by dividing by the xylem cross-sectional area $\left(\mathrm{m}^{2}\right)$.

Predawn native embolism was determined on 6-8 branches from 6-8 plants of each species. The procedures for collecting and transporting the samples were the same as those for the hydraulic conductivity test. Shoots were maintained in the laboratory with the cut ends immersed in water for ca. $30 \mathrm{~min}$ to release the tension, and the leaves were then excised under water to further release the tension (Wheeler et al., 2013). Approximately six 3-cm-long stem segments with diameter about $4.0 \mathrm{~mm}$ were excised under water at a distance $>120 \%$ of the maximum vessel length from the cut end and mounted on the XYL'EM apparatus. The native $K_{\mathrm{h}}$ was determined as before. The maximum $K_{\mathrm{h}}$ was measured similarly to native $K_{\mathrm{h}}$ but after removing embolisms from the segments by flushing them with the same solution at a pressure of $0.15 \mathrm{MPa}$ for $3 \mathrm{~min}$. The percentage loss of conductivity $(P L C, \%)$ was calculated by expressing native $K_{\mathrm{h}}$ as a percentage of maximum $K_{\mathrm{h}}$ :

$$
P L C=\left(1-\text { native } K_{\mathrm{h}} / \text { maximum } K_{\mathrm{h}}\right) \times 100 \text {. }
$$

\subsubsection{Stem vulnerability curves (VCs) by bench dehydration}

S. psammophila and C. korshinskii have relatively long vessels, so we used a bench dehydration method to measure the VCs to avoid the errors caused by open vessels in other methods (Cochard et al., 2013). The collection of samples was the same as for the measurements of predawn hydraulic conductivity. The collected branches were allowed to dehydrate gradually in the laboratory. Prior to the determinations of xylem water potential $\left(\psi_{\mathrm{x}}\right)$, the branches were sealed into a plastic bag containing wet paper towels inside for a minimum of $2 \mathrm{~h}$ to allow the equilibrium between $\psi_{1}$ and $\psi_{\mathrm{x}} . \psi_{\mathrm{x}}$ was then determined in two leaves per branch with a pressure chamber. We determined the mean $P L C$ in six 3-cm-long shoot segments per branch at different times during dehydration to increase the range of $\psi_{\mathrm{x}}$ values. PLC was determined following the same procedure as for the measurements of predawn native embolism described above.

The $P L C$ data were then binned for each $\psi_{\mathrm{x}}$ and curve-fitted to the binned data. Because the stems were not flushed when the VCs were measured by the bench dehydration method, we used Eq. 4 (Wang et al., 2014) to factor out the native PLC (NPLC) from the bench dehydration VCs:

$$
P L C_{\text {adj }}\left(\psi_{\mathrm{x}}\right)=\frac{\left[P L C\left(\psi_{\mathrm{x}}\right)-N P L C\right]}{100-N P L C} \times 100 .
$$

Where, $P L C_{\text {adj }}\left(\psi_{\mathrm{x}}\right)$ is the adjusted $P L C$ at $\psi_{\mathrm{x}}$ and $P L C\left(\psi_{\mathrm{x}}\right)$ is the $P L C$ measured by the bench dehydration method at any $\psi_{\mathrm{x}}$ before correction for $N P L C$. The sigmoidal function $P L C=100 /\left(1+\exp \left(a\left(\psi_{\mathrm{x}}-\psi_{50}\right)\right)\right)$ was used to model the VCs (Pammenter and van der Willigen, 1998). Where, $a$ is a constant related to the curve slope.

\subsubsection{Minimum xylem water potential and safety margin}

Daily courses of leaf and shoot xylem water potentials were measured on four plants per species on two sunny summer days. Measurements began at dawn and were repeated at an interval of $2 \mathrm{~h}$ throughout the day. At each measurement time, the water potentials of four covered and four sun-exposed leaves ( $\psi_{\mathrm{x}}$ and $\psi_{1}$, respectively) from four plants were measured. We estimated seasonal xylem potential by the methods presented by Pinto et al. (2012), in which a linear 
regression between shoot $\psi_{\mathrm{x}}$ and $\psi_{1}$ was developed based on the Darcy's law (Eq. 5).

$$
\psi_{\mathrm{x}} / \psi_{1, \mathrm{pd}}=\alpha+(1-\alpha)\left(\psi_{1} / \psi_{1, \mathrm{pd}}\right) \text {. }
$$

Where, $\psi_{1, \mathrm{pd}}$ is the predawn $\psi_{1}$; and $\alpha$ is the ratio of the petiole hydraulic resistance to the total resistance in the soil-to-leaf pathway, which can be considered as approximately constant. Data from the two species all fit the linear relationship well, so we deduced the seasonal $\psi_{\mathrm{x}}$ from the seasonal $\psi_{1}$ and calculated the hydraulic safety margins at which the shoots of both species operated (Hacke et al., 2000; Pockman and Sperry, 2000).

\subsubsection{Stem xylem anatomy and wood density}

Stem xylem traits were measured on a sub-sample of the segments used for building the VCs. Transverse sections were handfully obtained, stained with safranine (1\%) for 1-3 min and then mounted with glycerin. The sections were viewed in a light microscope (Olympus BX41, Olympus Austria, Vienna, Austria) interfaced with a CCD (Mingmei Electronin Ltd., Guangzhou, China). Three sectors at $120^{\circ}$ intervals were measured per section for a minimum of 250 vessels per stem. Anatomical parameters were analyzed by image analysis software (ImageJ 1.37, National Institutes of Health, Bethesda, MD, USA). Mean vessel diameter ( $d_{\text {mean }}$, assuming a circular shape), vessel density (vessels $/ \mathrm{mm}^{2}$ ) and conductive area (percentage of cross-sectional area occupied by vessels) were calculated from the cross-sectional conduit areas, averaged per sample. The average hydraulic conduit diameter $\left(d_{\mathrm{h}}\right)$ of each sample was calculated as $\sum d_{\mathrm{i}}{ }^{5} \sum d_{\mathrm{i}}{ }^{4}$ (Sperry et al., 1994). We also measured the wall thickness to span ratio $(t / b)_{\mathrm{h}}{ }^{2}$ (Hacke et al., $2001)$ to characterize the conduit wall reinforcement. The thickness of tangential interconduit walls $(t)$ and the conduit diameter $(b)$ were directly measured for conduit pairs with average diameters within $d_{\mathrm{h}} \pm 5 \mu \mathrm{m}$.

Stem segments approximately $2 \mathrm{~cm}$ in length were soaked in distilled water for at least one week for measuring wood density (dry weight per fresh volume) by using the method of Hacke et al. (2000), with the fresh volume determined by Archimedes' principle. The segments were immersed with a needle in a water-filled tray on a balance. The fresh volume was determined from the displacement weight. The samples were then dried in an oven at $80^{\circ} \mathrm{C}$ for $48 \mathrm{~h}$ and their dry weights were then measured.

\subsection{Statistical analysis}

Interspecific differences of hydraulic and anatomical traits were compared by independent-sample $t$-tests. The statistical analysis was performed using SPSS 15.0 (SPSS for Windows, Chicago, IL, USA).

\section{Results}

\subsection{Seasonal changes of environmental factors and leaf water potential}

Precipitation during the growth period of plants from April to October 2014 was $425.8 \mathrm{~mm}$, near the average of $410.8 \mathrm{~mm}$ for the previous ten years. About $62 \%$ of the precipitation occurred between July and September, with a daily maximum of $34 \mathrm{~mm}$ (Fig. 2). Daily $R_{\mathrm{S}}$ and vapor pressure deficit $(V P D)$ fluctuated during the growth season. $R_{\mathrm{s}}$ was relatively high from May to July and gradually declined thereafter, and $V P D$ never exceeded $2 \mathrm{kPa}$ except at the end of May and it trended downward from June to the end of October. Although the environmental factors varied seasonally, the values of predawn $\psi_{1}$ were relatively stable at $-0.30 \mathrm{MPa}$ in $S$. psammophila and $-0.52 \mathrm{MPa}$ in C. korshinskii. Midday $\psi_{1}$ in S. psammophila was also relatively stable at $-0.94 \mathrm{MPa}$, with slightly decreasing only at the end of the growth season due to foliar senescence, indicating that $S$. psammophila had a stricter seasonal stomatal regulation. Midday $\psi_{1}$ in $C$. korshinskii was relatively stable at about $-1.72 \mathrm{MPa}$ from May to July and gradually declined to $-2.4 \mathrm{MPa}$ at the end of the growth season, but it was always lower than that in $S$. psammophila throughout the season. Midday $\psi_{1}$ in C. korshinskii was lower at the end of the growth stage when $V P D$ was not so high and soil moisture in the root zone (inferred from the predawn $\psi_{1}$ ) was not deficient, suggesting that midday $\psi_{1}$ was uncoupled from the seasonal variation of $V P D$ and soil moisture. 

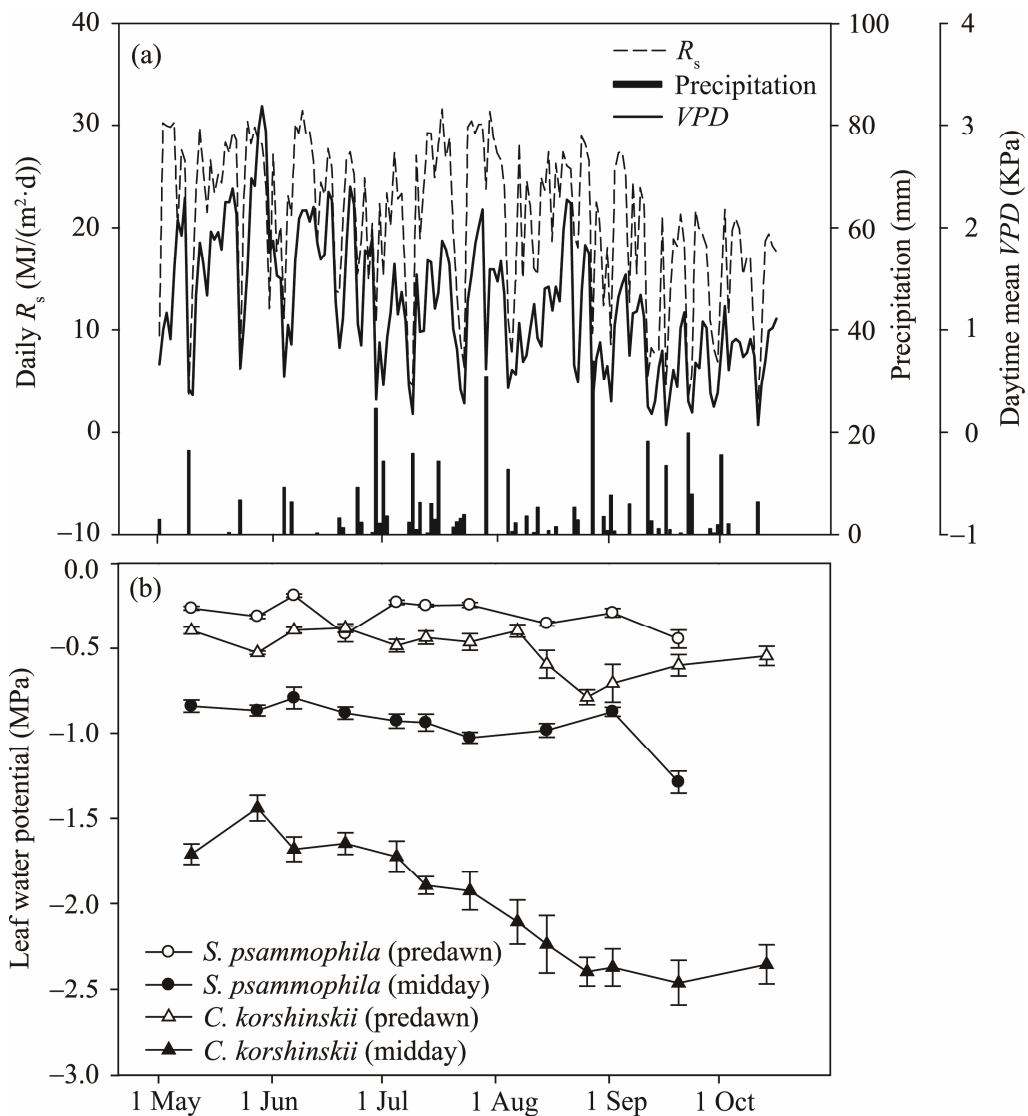

Fig. 2 Seasonal variations of environmental factors (a) and leaf water potentials (b) in S. psammophila and C. korshinskii during the growth period of 2014. The error bar indicates mean $\pm \mathrm{SE}$ for four plants of each species. $R_{\mathrm{s}}$, solar radiation; $V P D$, vapor pressure deficit.

\subsection{Stem vulnerability to cavitation in the two shrubs}

The values of mean maximum $K_{\mathrm{s}}$ in two-year-old regenerated shoots of $S$. psammophila and $C$. korshinskii were 10.17 and $4.32 \mathrm{~kg} /(\mathrm{s} \cdot \mathrm{MPa} \cdot \mathrm{m})$, respectively. This difference was significant, indicating that $S$. psammophila stems have higher water transport efficiency (Table 2). The values of predawn native PLC were $14.8 \%$ in S. psammophila and $39.7 \%$ in C. korshinskii. The model parameter $a$ was higher in the VC of $S$. psammophila stems (3.85) than in that of $C$. korshinskii (1.57; Fig. 3), indicating that the loss of hydraulic conductivity occurred within a narrower range in S. psammophila. The values of stem $\psi_{\mathrm{x}}$ inducing $12 \%, 50 \%$ and $88 \%$ loss of conductivity (corresponding to $\psi_{\mathrm{x}}$ at the onset of cavitation, at catastrophic hydraulic failure and at hydraulic failure, respectively) were $-1.11,-1.63$ and $-2.15 \mathrm{MPa}$ in $S$. psammophila, respectively, and $-1.37,-2.64$ and $-3.91 \mathrm{MPa}$ in $C$. korshinskii, respectively (Table 2). Thus, $C$. korshinskii stems were more resistant to cavitation than S. psammophila stems.

Table 2 Stem specific hydraulic conductivities $\left(K_{\mathrm{s}}\right)$ and modeling parameters of the vulnerability curves (VCs)

\begin{tabular}{|c|c|c|c|c|c|}
\hline \multirow{2}{*}{ Species } & \multirow{2}{*}{$\begin{array}{c}K_{\mathrm{s}} \\
(\mathrm{kg} /(\mathrm{s} \cdot \mathrm{MPa} \cdot \mathrm{m}))\end{array}$} & \multirow{2}{*}{$a$} & $\psi_{12}$ & $\psi_{50}$ & $\psi_{88}$ \\
\hline & & & \multicolumn{3}{|c|}{ (MPa) } \\
\hline S. psammophila & $10.17 \pm 0.17^{*}$ & 3.85 & -1.11 & -1.63 & -2.15 \\
\hline C. korshinskii & $4.32 \pm 1.13$ & 1.57 & -1.37 & -2.64 & -3.91 \\
\hline
\end{tabular}

Note: The curves were modeled with the sigmoidal function $P L C=100 /\left(1+\exp \left(a\left(\psi_{\mathrm{x}}-\psi_{50}\right)\right)\right)$. Where, $a$ is a constant related with slope of the curve. $\psi_{12}, \psi_{50}$ and $\psi_{88}$ correspond to stem water potentials at $12 \%, 50 \%$ and $88 \%$ loss of conductivity, respectively. ${ }^{*}$ indicates significant difference at $P<0.05$ level by an independent-sample $t$-test. Mean $\pm \mathrm{SE}$ for six stems from six plants of each species. 


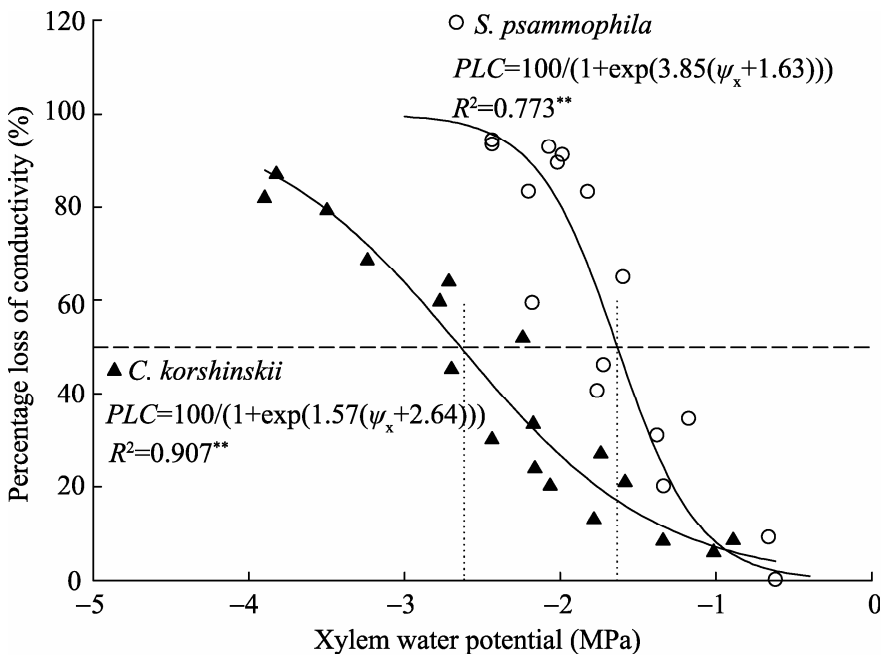

Fig. 3 Stem xylem vulnerability curves (VCs) for S. psammophila and C. korshinskii. The horizontal dashed line indicates $50 \%$ loss of conductivity; and the left and right vertical dotted lines correspond to $\psi_{50}$ for the stems of S. psammophila and C. korshinskii, respectively. ${ }^{* *}$ means significance at $P<0.01$ level.

\subsection{Seasonal minimum xylem water potential and hydraulic safety margin}

Leaf and stem $\psi_{\mathrm{x}}$ were similar in the early morning and late afternoon, while differed more in the midday for both shrubs. This difference was more evident in C. korshinskii than in S. psammophila, due to the much lower midday $\psi_{1}$ in C. korshinskii (Fig. 4a). The linear relationships between $\psi_{\mathrm{x}} / \psi_{1, \mathrm{pd}}$ and $\psi_{1} / \psi_{1, \mathrm{pd}}$ (Fig. 4b) for the two species allowed us to predict stem $\psi_{\mathrm{x}}$ from the seasonal predawn and midday $\psi_{1}$ (Fig. 2b). The values of seasonal minimum xylem water potential were $-0.95 \mathrm{MPa}$ in $S$. psammophila and $-1.46 \mathrm{MPa}$ in $C$. korshinskii. Inputting these values in the modeling vulnerability curves, we evaluated that the most critical embolism level for stems under field condition corresponded to PLCs of $6.69 \%$ for S. psammophila and $15.98 \%$ for C. korshinskii. Because the VCs have factored out the effect of native $P L C$, if we assumed the native predawn PLC did not vary seasonally, the in situ maximum losses of conductivity in shoots were $20.5 \%$ in $S$. psammophila and $49.3 \%$ in C. korshinskii. The estimated safety margins above $\psi_{50}$ were $0.68 \mathrm{MPa}$ for S. psammophila and $1.18 \mathrm{MPa}$ for C. korshinskii.
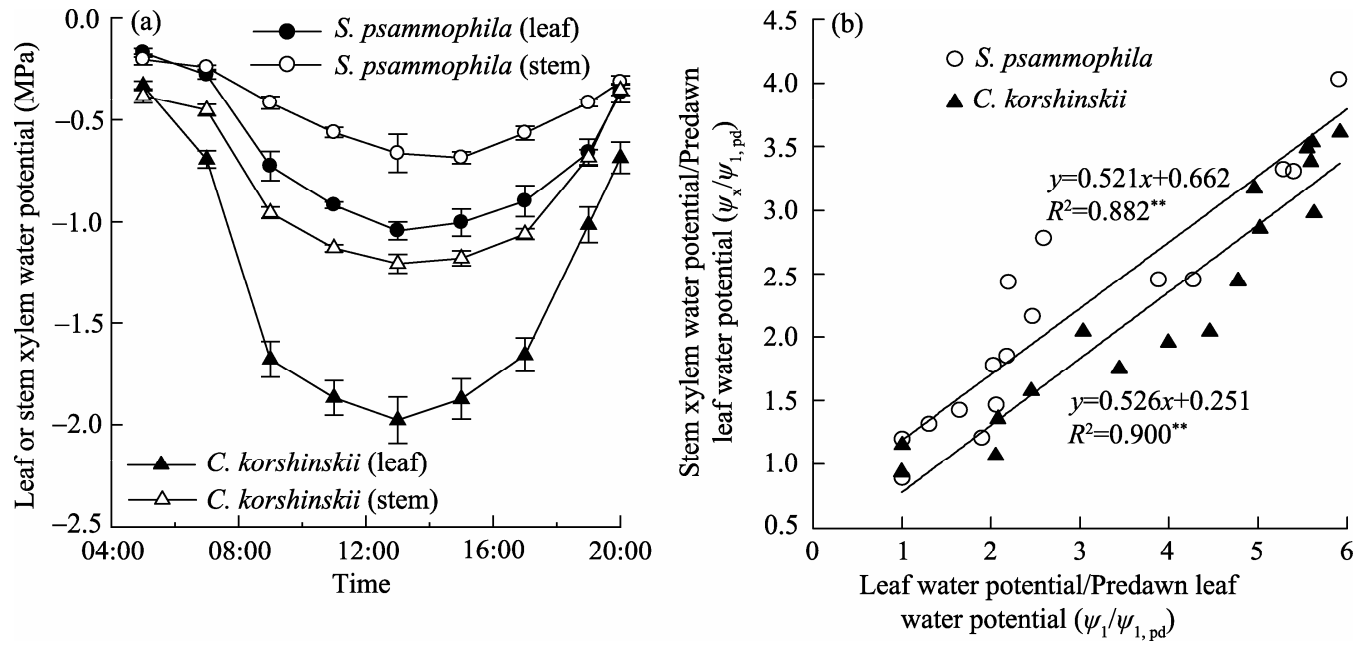

Fig. 4 Daily changes of leaf and stem xylem water potentials (a) and the relationships between $\psi_{1} / \psi_{1}$, pd and $\psi_{\mathrm{x}} / \psi_{1, \mathrm{pd}}$ (b) for $S$. psammophila and C. korshinskii based on measurements on two sunny days. Stem xylem water potential was gauged by the water potential of covered leaves measured on 20 July and 21 August 2014. Mean \pm SE for four plants per species at each measuring time. ${ }^{* *}$ means significance at $P<0.01$ level. 


\subsection{Anatomical traits of the stem wood}

S. psammophila had a longer maximum vessel length than $C$. korshinskii, but its mean conduit length was relatively shorter. Mean vessel diameters did not differ significantly between the two species, but $C$. korshinskii had a larger hydraulic diameter, which may be attributed to the larger vessels in early wood in ring-porous $C$. korshinskii. Vessel density and conductive area in $S$. psammophila were $62.7 \%$ higher and $25.6 \%$ larger than those in C. korshinskii, respectively. The wall thickness to span ratio did not differ between the two shrubs, but the wood density was lower in S. psammophila than in C. korshinskii (Table 3).

The distributions of vessel diameter were unimodal for both species. For S. psammophila, $64 \%$ of the vessel diameters were within the range of $20-35 \mu \mathrm{m}$, and the vessel diameters of $25-40 \mu \mathrm{m}$ contributed to $75 \%$ of the specific hydraulic conductivity. For $C$. korshinskii, 36\% of the vessel diameters were within the range of 10-20 $\mu \mathrm{m}$ and $37 \%$ were within the range of $20-35 \mu \mathrm{m}$, and the vessel diameters of $30-55 \mu \mathrm{m}$ contributed to $77 \%$ of the specific hydraulic conductivity (Fig. 5). S. psammophila had a larger percentage of medium-sized conduits (20-35 $\mu \mathrm{m})$, while $C$. korshinskii had a larger percentage of smaller conduits $(5-20 \mu \mathrm{m})$. Vessels larger than $40 \mu \mathrm{m}$ in diameter contributed more to hydraulic efficiency in C. korshinskii than in S. psammophila.

Table 3 Wood anatomical traits of S. psammophila and C. korshinskii stems

\begin{tabular}{|c|c|c|c|c|}
\hline Anatomical trait & S. psammophila & C. korshinskii & $P$ & $n$ \\
\hline Maximum xylem length $(\mathrm{cm})$ & $108 \pm 5$ & $71 \pm 1$ & ** & 6 \\
\hline Mean conduit length $(\mathrm{cm})$ & $17.4 \pm 1.6$ & $23.2 \pm 1.6$ & * & 6 \\
\hline Vessel diameter $(\mu \mathrm{m})$ & $28.59 \pm 1.11$ & $27.60 \pm 0.99$ & ns & 5 \\
\hline Hydraulic weighted diameter $(\mu \mathrm{m})$ & $34.21 \pm 1.51$ & $41.57 \pm 2.01$ & *** & 5 \\
\hline Vessel density (vessels $/ \mathrm{mm}^{2}$ ) & $262 \pm 21$ & $161 \pm 17$ & *** & 5 \\
\hline Conductive area (\%) & $12.32 \pm 0.64$ & $9.81 \pm 0.40$ & ${ }^{* * *}$ & 5 \\
\hline Wall thickness to span ratio $(t / b)^{2}{ }_{\mathrm{h}}$ & $0.026 \pm 0.003$ & $0.026 \pm 0.005$ & ns & 5 \\
\hline Wood density $\left(\mathrm{g} / \mathrm{cm}^{3}\right)$ & $0.462 \pm 0.013$ & $0.630 \pm 0.030$ & * & 9 \\
\hline
\end{tabular}

Note: The significance of the differences between the two species was tested by the independent-sample $t$-tests. ${ }^{*},{ }^{* *}$ and ${ }^{* * *}$ indicate significance at $P<0.05, P<0.01$ and $P<0.001$ levels, respectively; ${ }^{\text {ns }}$ means significance at $P>0.05$ level. Mean \pm SE. $n$ is the number of sampled branches.

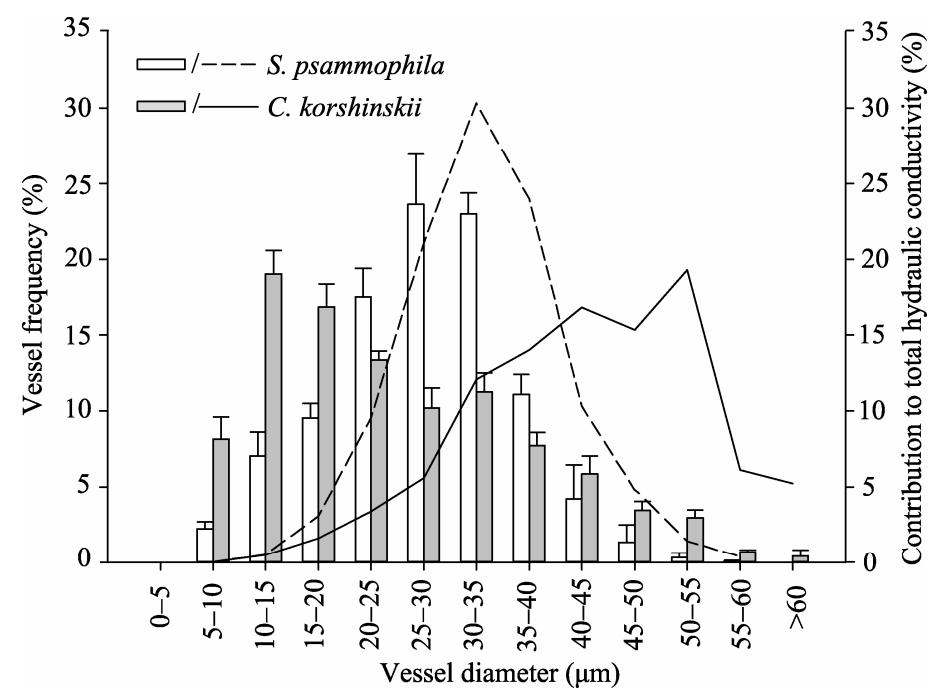

Fig. 5 Distributions of vessel diameters and their contribution to the total hydraulic conductivities in $S$. psammophila and $C$. korshinskii. The histograms and lines indicate vessel frequency and contribution to total hydraulic conductivity, respectively. Mean \pm SE for five stems per species. 


\section{Discussion}

\subsection{Stem hydraulic vulnerability to cavitation in the two shrubs}

Stem $\psi_{50}$ in $S$. psammophila was $-1.63 \mathrm{MPa}$, more negative than the $-1.18 \mathrm{MPa}$ reported for current stems of young plants of this species (Ogasa et al., 2013) but within the range reported for other willows (Cochard et al., 2007; Wikberg and Ögren, 2007). Stem $\psi_{50}$ in C. korshinskii was $-2.54 \mathrm{MPa}$, essentially the same as the mean $\psi_{50}(-2.66 \mathrm{MPa})$ for winter deciduous shrubs (Maherali et al., 2004). Hydraulic vulnerability to drought-induced cavitation varies with soil water availability, rooting depth, vegetative phenology and plant water status during drought (Hacke et al., 2000). Species in more xeric environments with deeper roots tend to have higher resistance to loss of hydraulic function compared to species in mesic environments with shallower roots (Pockman and Sperry, 2000; Bucci et al., 2013). Shallow-rooted and drought-deciduous shrubs in the Great Basin of Utah had the lowest water potential prior to leaf shedding and had the most resistant xylems, and the phreatophytic shrub Chrysothamnus nauseosus always maintained favorable water potentials and had the most susceptible xylem to cavitation (Hacke et al., 2000). S. psammophila is a water-spending species and usually accesses water by extensive roots (Dong and Zhang, 2001). The seasonal changes of midday $\psi_{1}$ were smaller in S. psammophila than in C. korshinskii, showing stricter stomatal regulation, resulting in water use strategies that allowed the maintenance of a higher seasonal $\psi_{1}$. S. psammophila was also more vulnerable to cavitation. The roots of $C$. korshinskii can extend to a depth of $6 \mathrm{~m}$, and the plants mainly get water from deeper soil layers (Niu et al., 2003). The midday $\psi_{1}$ for $C$. korshinskii in our study declined in the later growth stages, possibly because the major source of water uptake changed from deeper soil layers in the dry season to shallower soil layers in the wet season. This premise is partly supported by a hydrogen isotope experiment in Wang et al. (2013). C. korshinskii may have evolved a stronger resistance to cavitation as an adaptation to resist the more negative seasonal minimum water potential.

Water-stress-induced xylem cavitation is caused by air seeding through pit pores. The larger and wider vessels usually have more pitted area, so they have a greater likelihood of containing a large noncavitation-resistant pit pore (Wheeler et al., 2005; Hacke et al., 2006). Longer vessels are less hydraulically limited by pit and end wall resistances, but they may have larger pit areas that increase the susceptibility to hydraulic failure via cavitation (Wheeler et al., 2005). The mean vessel size did not differ between the two shrubs in our study. S. psammophila had a longer maximum vessel length with a shorter mean vessel length, suggesting that maximum vessel length may not always be a good predictor of mean vessel length. Air permeability was constant in S. psammophila during the cutting experiment after a certain distance from the maximum xylem length, suggesting that few longer vessels can play important role in stem water transport. S. psammophila also had a higher vessel density and a larger conductive area than C. korshinskii, which may increase conduit connectivity and possibly intervessel pit membrane area per vessel and thus the likelihood of a large pit pore that triggers air-seeding. Cavitation-resistant xylems were strongly correlated with high wood densities (Hacke et al., 2001), and our data for $C$. korshinskii support this point. The wall thickness to span ratio $(t / b)_{\mathrm{h}}{ }^{2}$ did not differ significantly between the two species, suggesting that there was no causal link between the vulnerability to cavitation and $(t / b)_{\mathrm{h}}{ }^{2}$, because they are located in different wall regions. Longer maximum vessel length, higher vessel density, larger conductive area and lower wood density are important anatomical traits in S. psammophila that may be responsible for its higher water transport capacity and weaker cavitation resistance.

\subsection{In situ embolism and safety margin}

The in situ maximum losses of conductivity in two-year-old shoots of $S$. psammophila and $C$. korshinskii under the most critical conditions were $20.5 \%$ and $49.3 \%$, respectively. The maximum degrees of embolism in S. psammophila and C. korshinskii were both lower than $20 \%$ when the effect of native PLC was removed, with the values of $6.7 \%$ and $16.0 \%$, respectively. These results suggested that cavitation can occur only when xylem pressure falls below a 
threshold pressure that woody plants experience only after prolonged episodes of drought. Recently discovered methodological problems (Cochard et al., 2013; Wheeler et al., 2013) suggested that embolisms may be far from routine in trees, contrary to what was believed previously. In this study, soil water potential in the root zone, inferred from predawn $\psi_{1}$, changed little over the different courses of the study period, indicating that the soil did not suffer severe drought in a year with normal precipitation. The level of embolism in the field was thus very low, implying that the regenerated shoots can function well for both shrubs.

The hydraulic safety margins were 0.69 and $1.07 \mathrm{MPa}$ in S. psammophila and C. korshinskii, respectively. A recent study reported that the stems of $70 \%$ of 226 forest species from 81 sites worldwide operate with narrow hydraulic safety margins of $<1 \mathrm{MPa}$ against catastrophic xylem dysfunction (Choat et al., 2012). The hydraulic safety margins of the two species in our study were also within or near this range, suggesting that unless they have a high capacity for embolism reversal, they could experience conditions when reductions in productivity and survival occur. Drought-resistant or xeric species tend to have a larger safety margin (Pockman and Sperry, 2000; Bucci et al., 2013), as did C. korshinskii. The widely hydraulic safety margins are likely a protective mechanism, preventing embolism in organs where it may be more damaging or where its reversal is less efficient.

A key component in the drought resistance of woody species is their ability to limit embolism formation, which can be achieved by the avoidance of high xylem tensions or by building a water transport pathway that is resistant to hydraulic failure. S. psammophila alleviated the threat of cavitation by maintaining stronger stomatal regulation, shown by its relatively stable seasonal midday $\psi_{1}$, while $C$. korshinskii resisted cavitation by structural reinforcement of its xylem. In addition, $C$. korshinskii can also shed its leaves during severe drought period, which can help to decrease the threat of cavitation. Meinzer et al. (2009) found that the avoidance of embolism in species with low wood density appears to be achieved primarily by reliance on the transient release of stored water to constrain transpiration-induced fluctuations in xylem tension. Although we did not measure the release of stored water, this mechanism may also possibly be important for S. psammophila to avoid cavitation. Daily embolism formation and refilling may also be an important mechanism for avoiding accumulated embolisms in highly vulnerable species (Salleo et al., 1996; Ogasa et al., 2013). This mechanism may occur in S. psammophila and further testing is required.

\section{Conclusions}

S. psammophila is more efficient in water transport but is more vulnerable to drought-induced cavitation than $C$. korshinskii, illustrating that $S$. psammophila is a water-consuming species susceptible to cavitation and $C$. korshinskii is a water-saving species resistant to cavitation. The shoots of the two shrubs lived comfortably above the most critical embolism thresholds in a year with normal precipitation, indicating that both shrubs are well adapted to the local dry desert environment and the regenerated shoots could function normally. S. psammophila mainly depends on strict stomatal control to avoid embolism, whereas $C$. korshinskii resists embolism by structural reinforcement of its xylem. Shorter maximum vessel length, lower vessel density, smaller conductive area and higher wood density in C. korshinskii may contribute to its stronger resistance to cavitation. These results have demonstrated some of the hydraulic mechanisms how the two shrubs cope with the dry desert environment of the southern Mu Us Sandy Land.

\section{Acknowledgments}

This study was supported by the National Natural Science Foundation of China (41371507).

\section{References}

Brodribb T J, Field T S. 2000. Stem hydraulic supply is linked to leaf photosynthetic capacity: evidence from New Caledonian and Tasmanian rainforests. Plant, Cell and Environment, 23(12): 1381-1388. 
Brodribb T J, Holbrook N M. 2005. Water stress deforms tracheids peripheral to the leaf vein of a tropical conifer. Plant Physiology, 137(3): 1139-1146.

Bucci S J, Scholz F G, Peschiutta M L, et al. 2013. The stem xylem of Patagonian shrubs operates far from the point of catastrophic dysfunction and is additionally protected from drought-induced embolism by leaves and roots. Plant, Cell and Environment, 36(12): 2163-2174.

Choat B, Jansen S, Brodribb T J, et al. 2012. Global convergence in the vulnerability of forests to drought. Nature, 491(7426): 752-755.

Cochard H, Froux F, Mayr S, et al. 2004. Xylem wall collapse in water-stressed pine needles. Plant Physiology, 134(1): 401-408.

Cochard H, Casella E, Mencuccini M. 2007. Xylem vulnerability to cavitation varies among poplar and willow clones and correlates with yield. Tree Physiology, 27(12): 1761-1767.

Cochard H, Barigah S T, Kleinhentz M, et al. 2008. Is xylem cavitation resistance a relevant criterion for screening drought resistance among Prunus species? Journal of Plant Physiology, 165(9): 976-982.

Cochard H, Badel E, Herbette S, et al. 2013. Methods for measuring plant vulnerability to cavitation: a critical review. Journal of Experimental Botany, 64(15): 4779-4791.

Cohen S, Bennink J, Tyree M. 2003. Air method measurements of apple vessel length distributions with improved apparatus and theory. Journal of Experimental Botany, 54(389): 1889-1897.

Delzon S, Cochard H. 2014. Recent advances in tree hydraulics highlight the ecological significance of the hydraulic safety margin. New Phytologist, 203(2): 355-358.

Dong X J, Zhang X S. 2001. Some observations of the adaptations of sandy shrubs to the arid environment in the Mu Us Sandland: leaf water relations and anatomic features. Journal of Arid Environments, 48(1): 41-48.

Ewers F W, Fisher J B. 1989. Techniques for measuring vessel lengths and diameters in stems of woody plants. American Journal of Botany, 76(5): 645-656.

Fan L M. 2007. Groundwater seepage caused by mining and the prevention strategies in the northern Shaanxi. Mining Safety and Environmental Protection, 34(5): 62-64. (in Chinese)

Fang X W, Turner N C, Xu D H, et al. 2013. Limits to the height growth of Caragana korshinskii resprouts. Tree Physiology, 33(3): 275-284.

Hacke U G, Sperry J S, Pittermann J. 2000. Drought experience and cavitation resistance in six shrubs from the Great Basin, Utah. Basic and Applied Ecology, 1(1): 31-41.

Hacke U G, Sperry J S, Pockman W T, et al. 2001. Trends in wood density and structure are linked to prevention of xylem implosion by negative pressure. Oecologia, 126(4): 457-461.

Hacke U G, Sperry J S, Wheeler J K, et al. 2006. Scaling of angiosperm xylem structure with safety and efficiency. Tree Physiology, 26(6): 689-701.

Hargrave K R, Kolb K J, Ewers F W, et al. 1994. Conduit diameter and drought-induced embolism in Salvia mellifera Greene (Labiatae). New Phytologist, 126(4): 695-705.

Jacobsen A L, Pratt R B, Ewers F W, et al. 2007. Cavitation resistance among 26 chaparral species of southern California. Ecological Monographs, 77(1): 99-115.

Ma C C, Gao Y B, Guo H Y, et al. 2008. Physiological adaptations of four dominant Caragana species in the desert region of the Inner Mongolia Plateau. Journal of Arid Environments, 72(3): 247-254.

Maherali H, Pockman W T, Jackson R B. 2004. Adaptive variation in the vulnerability of woody plants to xylem cavitation. Ecology, 85(8): 2184-2199.

Mayr S, Hacke U, Schmid P, et al. 2006. Frost drought in conifers at the alpine timberline: xylem dysfunction and adaptations. Ecology, 87(12): 3175-3185.

Meinzer F C, Johnson D M, Lachenbruch B, et al. 2009. Xylem hydraulic safety margins in woody plants: coordination of stomatal control of xylem tension with hydraulic capacitance. Functional Ecology, 23(5): 922-930.

Nardini A, Battistuzzo M, Savi T. 2013. Shoot desiccation and hydraulic failure in temperate woody angiosperms during an extreme summer drought. New Phytologist, 200(2): 322-329.

Niu X W, Ding Y C, Zhang Q, et al. 2003. Studies on the characteristics of Caragana root development and some relevant physiology. Acta Botanica Boreali-Occidentalia Sinica, 23(5): 860-865. (in Chinese)

Ogasa M, Miki N H, Murakami Y, et al. 2013. Recovery performance in xylem hydraulic conductivity is correlated with cavitation resistance for temperate deciduous tree species. Tree Physiology, 33(4): 335-344.

Pammenter N W, van der Willigen C. 1998. A mathematical and statistical analysis of the curves illustrating vulnerability of xylem to cavitation. Tree Physiology, 18(8-9): 589-593. 
Pinto C A, David J S, Cochard H, et al. 2012. Drought-induced embolism in current-year shoots of two Mediterranean evergreen oaks. Forest Ecology and Management, 285: 1-10.

Pockman W T, Sperry J S. 2000. Vulnerability to xylem cavitation and the distribution of Sonoran desert vegetation. American Journal of Botany, 87(9): 1287-1299.

Pratt R B, Ewers F W, Lawson M C, et al. 2005. Mechanisms for tolerating freeze-thaw stress of two evergreen chaparral species: Rhus ovata and Malosma laurina (Anacardiaceae). American Journal of Botany, 92(7): 1102-1113.

Salleo S, Gullo M A, de Paoli D, et al. 1996. Xylem recovery from cavitation-induced embolism in young plants of Laurus nobilis: a possible mechanism. New Phytologist, 132(1): 47-56.

Sperry J S, Tyree M T. 1988. Mechanism of water stress-induced xylem embolism. Plant Physiology, 88(3): 581-587.

Sperry J S, Nichols K L, Sullivan J E M, et al. 1994. Xylem embolism in ring-porous, diffuse-porous, and coniferous trees of northern Utah and interior Alaska. Ecology, 75(6): 1736-1752.

Sperry J S, Hacke U G, Wheeler J K. 2005. Comparative analysis of end wall resistivity in xylem conduits. Plant, Cell and Environment, 28(4): 456-465.

Tyree M T, Sperry J S. 1989. Vulnerability of xylem to cavitation and embolism. Annual Review of Plant Physiology and Plant Molecular Biology, 40(1): 19-36.

Tyree M T, Davis S D, Cochard H. 1994. Biophysical perspectives of xylem evolution: is there a tradeoff of hydraulic efficiency for vulnerability to dysfunction? IAWA Journal, 15(4): 335-360.

Walter H, Box E O. 1983. The desert of central Asia. In: West N E. Ecosystems of the World (Vol. 5): Temperate Deserts and Semi-Deserts. Amsterdam: Elsevier, 193-236.

Wang L, Mu Y, Zhang Q F, et al. 2013. Groundwater use by plants in a semi-arid coal-mining area at the Mu Us Desert frontier. Environmental Earth Sciences, 69(3): 1015-1024.

Wang R Q, Zhang L L, Zhang S X, et al. 2014. Water relations of Robinia pseudoacacia L.: do vessels cavitate and refill diurnally or are R-shaped curves invalid in Robinia? Plant, Cell and Environment, 37(12): 2667-2678.

Wheeler J K, Sperry J S, Hacke U G, et al. 2005. Inter-vessel pitting and cavitation in woody Rosaceae and other vesselled plants: a basis for a safety versus efficiency trade-off in xylem transport. Plant, Cell and Environment, 28(6): 800-812.

Wheeler J K, Huggett B A, Tofte A N, et al. 2013. Cutting xylem under tension or supersaturated with gas can generate PLC and the appearance of rapid recovery from embolism. Plant, Cell and Environment, 36(11): 1938-1949.

Wikberg J, Ögren E. 2007. Variation in drought resistance, drought acclimation and water conservation in four willow cultivars used for biomass production. Tree Physiology, 27(9): 1339-1346.

Xu B C, Shan L. 2004. A comparative study on water use characteristics and eco-adaptability of Hippophae rhamnoides and Caragana korshinskii in semi-arid loess hilly-gully region. Chinese Journal of Applied Ecology, 15(11): 2025-2028. (in Chinese)

Zhang L, Wu B, Ding G D, et al. 2010. Root distribution characteristics of Salix psammophyla and Caragana korshinskii in Mu Us sandy land. Journal of Arid Land Resources and Environment, 24(3): 158-161. (in Chinese)

Zimmermann M H. 1983. Xylem Structure and the Ascent of Sap. Berlin: Springer-Verlag, 96-106. 